\title{
Rancang Bangun Website Pemesanan Makanan Kedai Twins Menggunakan Laravel Php Framework
}

\author{
Niko Cahyono Slamet Muljono ${ }^{1}$; Devina Gunadi ${ }^{2}$; Agus Cahyo Nugroho ${ }^{3}$ \\ Program Studi Sistem Informasi, Fakultas Ilmu Komputer Unika Soegijapranata \\ email: nikocahyono19@gmail.com ${ }^{1}$; devinagunadi32125@ gmail.co.id ${ }^{2}$; \\ agus.nugroho@unika.ac.id ${ }^{3}$
}

\begin{abstract}
The growing use of Information Systems has become a necessity, this development also has an impact on the services of a business. Likewise, what happened to the Twins shop, which is one of the eateries favored by Unika students, although it has been helped by the presence of an official account via Line and Whatsapp, the order process is still chaotic and the recording is done manually. Web-Twins was created to simplify the online ordering process, and provide information to the Twins shop. This website is designed using Laravel, PHP language, and uses the MySQL database. The presence of this website is expected to help the Twins shop in managing incoming order data and improving the quality of order delivery.
\end{abstract}

Keywords: E-Commerce, PHP Framework, Laravel

\begin{abstract}
Abstrak
Berkembangnya penggunaan Sistem Informasi, menjadi suatu kebutuhan, perkembangan ini juga memberikan dampak pada layanan suatu usaha. Begitu pula yang terjadi pada kedai Twins, yang merupakan salah satu kedai makan yang digemari oleh mahasiswa Unika, meskipun telah terbantu dengan hadirnya official account melalui Line dan Whatsapp, tapi proses pemesanan tersebut masih kacau dan pencatatannya dilakukan secara manual. WebTwins ini dibuat untuk mempermudah dalam melakukan proses pemesanan secara online, dan memberikan informasi pada kedai Twins. Website ini dirancang menggunakan Laravel, bahasa PHP, dan menggunakan database MySQL. Hadirnya website ini diharapkan dapat membantu kedai Twins dalam mengelola data pesanan masuk, dan meningkatkan kualitas pengiriman pesanan.
\end{abstract}

\section{Kata kunci: E-Commerce, PHP Framework, Laravel}

\section{PENDAHULUAN}

\section{I.1 Latar Belakang}

Semakin berkembangnya jaman
kebutuhan akan penggunaan sistem
informasi sangatlah penting dan dibutuhkan.
Pesatnya perkembangan sistem informasi ini
mempengaruhi berbagai macam bidang
usaha, pekerjaan, dan juga aktivitas sehari-
hari secara global. Salah satu bidang usaha

yang terkena dampak dari perkembangan ini adalah bidang usaha jual beli.

Pada jaman dahulu sistem jual beli yang dilakukan adalah bersifat konvensional, dimana antara penjual dan pembeli harus bertemu secara langsung disuatu tempat dan waktu tertentu. Tetapi hal tersebut dianggap tidak efektif dan efisien untuk beberapa orang, hal ini dikarenakan keterbatasan waktu dan tempat yang dimiliki. Oleh sebab itu munculah e-commerce yang dapat 
mempermudah transaksi tersebut. Ecommerce adalah penyebaran, pembelian, penjualan, pemasaran barang dan jasa melalui sistem elektronik seperti internet atau televisi, website, atau jaringan komputer lainnya.

Oleh karena dari itu kami memiliki ide untuk membuatkan suatu website untuk kedai "Twins" yang kami beri nama WebTwins. Kedai "Twins" sendiri merupakan kedai makan sederhana yang cukup terkenal di daerah Universitas Katolik Soegijapranata, Semarang. Mereka menyediakan berbagai makanan dan minuman rumahan yang sangat lezat, dengan harga yang ekonomis, sehingga banyak sekali pelanggan yang membeli di kedai ini. Alasan kami membuat website untuk kedai tersebut, karena kami melihat terdapat banyak sekali transaksi jual dan beli yang terjadi, tetapi transaksi tersebut masih dilakukan secara konvensional dan hanya menggunakan bantuan Official Account di Line. Dan untuk mempermudah transaksi yang ada maka kami berinisiatif untuk membuat website yang dapat digunakan oleh user dan juga admin mereka sendiri.

Kami berharap dengan adanya website ini semua transaksi yang ada bisa dilakukan secara lebih cepat dan teratur. Sehingga admin maupun user mendapatkan keuntungan yang sama, diantarnya adalah transaksi lebih cepat, proses pelayanan juga cepat, bisa dilakukan dimana saja, dan dapat lebih teratur

\section{I.2 Metode Penelitian}

Perancangan web-Twins dilakukan dengan studi pustaka yaitu penulis mengumpulkan refrensi dari jurnal,artikel, video, dan buku mengenai penggunaan website sebagai media komunikasi kedai makan. Setelah itu dilanjutkan dengan mengamati dan mencoba website maupun media lain yang membahas mengenai sistem pemesanan kedai makan. Kemudian dilakukan implementasi ke kedai Twins yang akan membantu proses pemesanan makanan dan beberapa fitur tambahan.

\section{TINJAUAN PUSTAKA}

\section{II.1 Profil Kedai Twins}

Salah satu kedai makan yang ada di sekitar Unika Soegijapranata. Kedai Twins didirikan oleh salah satu alumni Unika Soegijapranata, dan sangat diminati oleh mahasiswa Unika Soegijapranata. Kedai Twins setiap harinya menyediakan berbagai menu rumahan yang berbeda-beda setiap harinya, sehingga pelanggan akan merasa makan di rumah sendiri. Kedai Twins selama ini dalam melakukan proses jual beli menggunakan fasilitas Lineat, Whatsapp untuk pelanggan di sekitar Unika Soegijapranata. Jika pelanggan berada jauh dari Unika Soegijapranata, maka dapat memesan makanan melalui Go-Food. Kedai Twins terletak di Jln. Pawiyatan Luhur no 57 Bendan Duwur, Gajah Mungkur, Tinjomoyo, Kec. Banyumanik, Kota Semarang. Jam operasional dari kedai ni adalah pukul 10.00 $-22.00 \mathrm{WIB}$

\section{II.2 Website}

Gregorius, 2000:30 mengatakan bahwa website merupakan kumpulan halaman yang berisi informasi dan saling terhubung satu sama lain. Sedangkan menurut Arief (2011:7) website adalah salah satu aplikasi dengan beragam dokumen multimedia yang disusun menggunakan protocol HTTP (Hypertext Transfer Protocol), untuk mengaksesnya memerlukan perangkat lunak atau biasanya lebih dikenal dengan browser[1].

\section{II.3 Tools Permodelan}

Berikut merupakan tools permodelan yang digunakan untuk perancangan website kedai Twins:

\section{II.3.1 Business Process Model and Notation (BPMN)}


Business Process Model and Notation merupakan proses diagram yang akan menggambarkan aktivitas operasi bisnis. Tujuan daru BPMN adalah untuk mendefinisikan langkah-langkah yang harus diambil untuk mengatasi hambatan yang ada pada proses bisnis[2].

\section{II.3.2 SQLyog}

SQLyog merupakan salah satu tools administrasi untuk pembuatan database MySQL. SQLyog dirancang untuk memudahkan pengguna MySQL untuk mengatur table dan record-record yang terdapat pada database MySq1[3].

\section{II.3.3 Use Case Diagram}

Use Case Diagram adalah diagram untuk menggambarkan hubungan antara sistem dan pengguna (aktor). Use Case hanya memberikan penggambaran secara global, sehingga pengguna terkadang kurang mendapatkan penggambaran secara detail[4].

\section{II.3.4 Laravel}

Laravel merupakan salah satu framework yang cukup populer di Indonesia. Framework ini berbasis PHP dan menggunakan metode MVC (Model, View, Controller). Laravel akan mempermudah developer dalam membangun sebuah website, karena developer tidak harus membuatnya dari awal[5].

\section{II.4 Tools Pembangunan Aplikasi}

\section{II.4.1 Bahasa Pemrograman PHP}

Merupakan bahasa pemrograman yang sering digunakan pada pembuatan web service-side yang bersifat open source. PHP sendiri kepanjangan dari Hypertext Processor, sehingga berisi bahasa pemrograman yang berbasis kode-kode yang digunakan untuk mengolah data dan mengirimkannya ke web server menjadi kode HTML[6].

\section{II.4.2 Bahasa Pemrograman HTML}

Merupakan text yang berbentuk link, ketika diklik maka akan membawa pengakses internet ke dokumen yang dituju. HTML sendiri kepanjangan dari Hyper Text Markup Language[7].

\section{ANALISIS DAN PERANCANGAN}

\section{III.1 Proses Bisnis}

Saat ini, kedai Twins masih menggunakan cara manual dalam melayani proses pemesanan makanan. Meskipun sekarang sudah terbantu dengan adanya official account dari Line dan Whatsapp, tetapi proses tersebut masih dilakukan secara manual. Seperti memberikan rincian menu kemudian mencatat menu yang dipesan oleh pelanggan. Dalam pencatatan tersebut bisa terjadi kesalahan jika terdapat banyak pesanan.

\section{III.1.1 Proses Bisnis Saat Ini}

Detail tahap proses pemesanan di kedai Twins adalah pertama pelanggan harus memiliki salah satu media sosial dari kedai Twins, kemudian pelanggan menanyakan detail menu pada salah satu media sosial. Pemilik akan menjawab pertanyaan chat tersebut, setelah mendapatkan menu pelanggan akan memberikan rincian pesanan dan lokasi pelanggan berada kepada kedai Twins. Apabila menu yang diinginkan ternyata habis, maka pemilik akan memberikan info melalui chat, jika menu yang dipesan masih tersedia maka pelanggan tinggal menunggu menu yang dipesan datang. Setelah menu yang dipesan datang, maka pelanggan melakukan pembayaran pada pengirim makanan. 


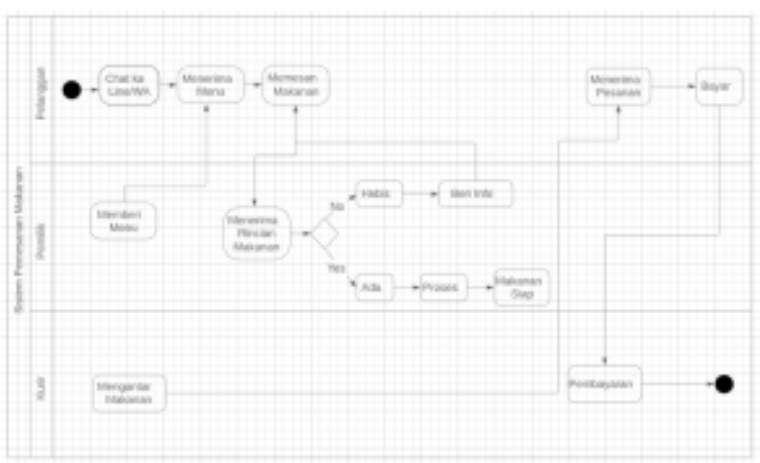

Gambar 3.1 Proses Bisnis Saat Ini

\section{III.1.2 Proses Bisnis Usulan}

Website ini dibuat agar pelanggan lebih cepat dalam memilih makanan. Detail tahap proses bisnis usulan adalah pelanggan cukup mengunjungi dan login website. Setelah pelanggan melihat menu apa saja yang ada di kedai Twins, maka pelanggan memilih dan memesan menu. Sistem dari admin akan menerima pesanan yang masuk dari pelanggan, dan akan langsung memprosesnya. Setelah menu yang dipesan datang, maka pelanggan melakukan pembayaran pada pengirim makanan.

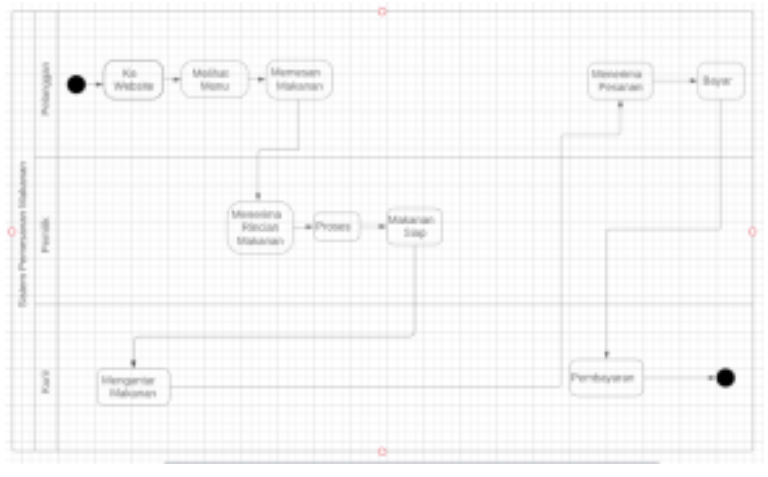

Gambar 3.2 Proses Bisnis Susulan

\section{III.2 Use Case Diagram}

Pada website web-Twins yang akan menjelaskan hubungan antara sistem dan pengguna (aktor). Hubungan ni dapat beruba input aktor ke sistem ataupun sebaliknya. Berikut adalah use case diagram website yang dibangun:

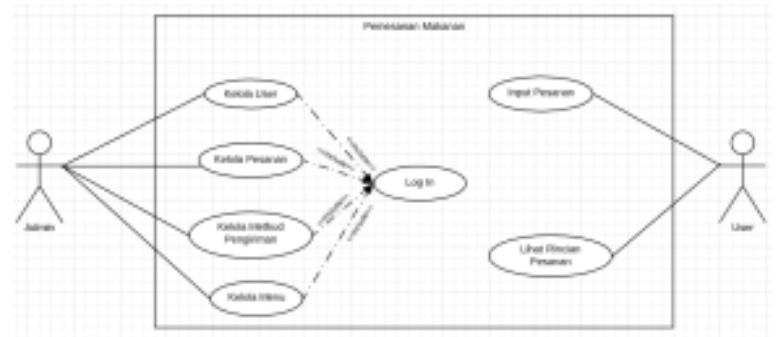

Gambar 3.3 Use Case

\section{HASIL DAN PEMBAHASAN}

IV.1. Halaman User

IV.1.1 Halaman Utama

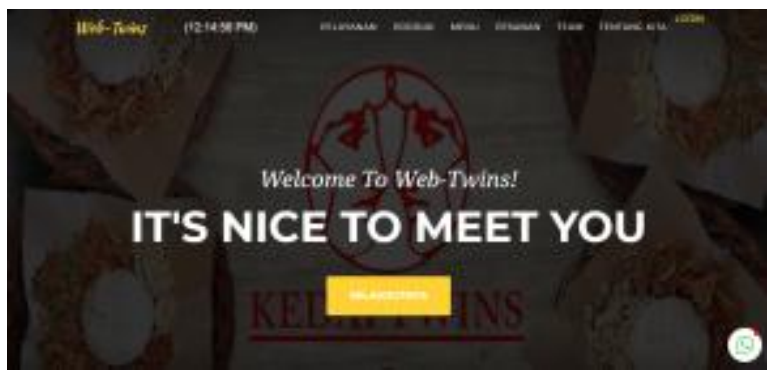

Gambar 4.1 Tampilan Halaman Utama

Pada halaman utama terdapat menu pelayanan, produk, menu, pesanan, team, tentang kita. Pada halaman ini juga terdapat menu untuk admin untuk login.

\section{IV,1,2 Halaman Produk}

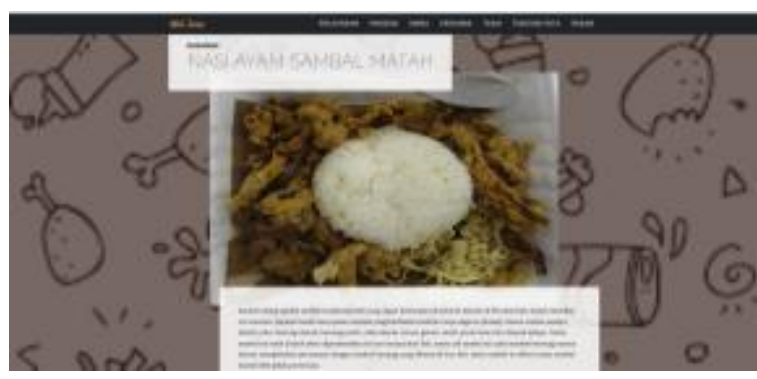

Gambar 4.2 Tampilan Halaman Produk

Pada halaman ini user akan mampu melihat menu makanan yang dijualkan oleh 
kedai Twins, disertai dengan foto dan keterangan dari makanan tersebut.

\section{IV.1.3 Halaman Pesanan}

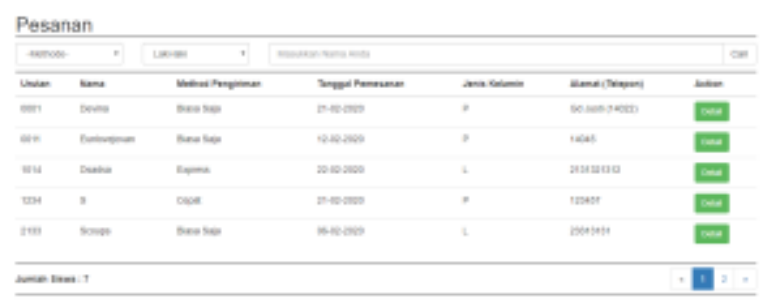

Gambar 4.3 Tampilan Halaman Pesanan

Diatas adalah tampilan untuk menu pesanan, disini user akan dapat melihat rincian pesanan yang telah diinputkan pada website.

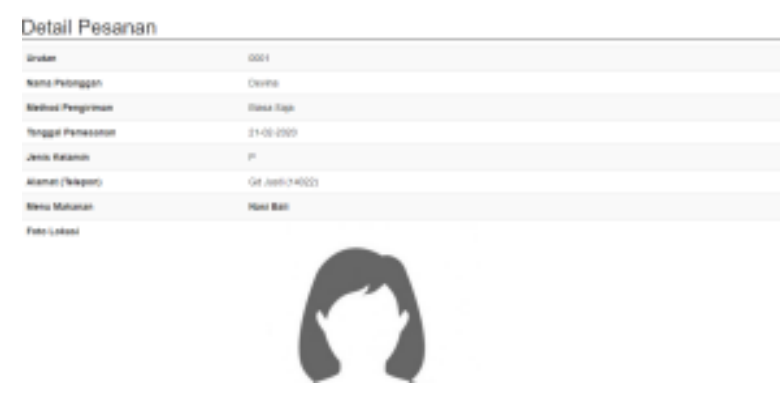

Gambar 4.4 Tampilan Edit Pesanan

Menu ini juga akan mempelihatkan detail pesanan secara lengkap disertai dengan foto lokasi user.

\section{IV.1.4 Halaman Pesan}

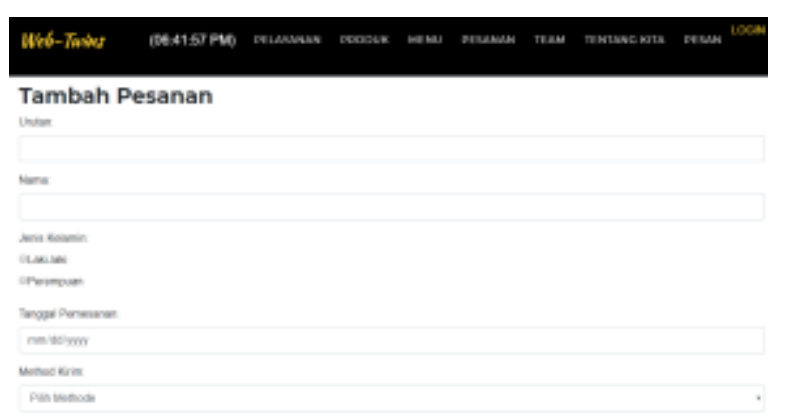

Gambar 4.5 Tampilan Halaman Pesan

Jika user ingin memesan makanan, maka user dapat dapat memesannya pada menu pesan. Pada halaman tersebut akan terdapat form rincian pesanan yang harus wajib diisi oleh user, karena jika ada beberapa data yang tidak diisi maka user tidak akan dapat menginput data pesanan.

\section{IV.2 Halaman Admin}

\section{IV.2.1 Halaman Log In}

Gambar 4.6 Tampilan Halaman Log In

Fungsi dari halaman ini adalah untuk mengelola data di dalam sistem, namun admin harus $\log$ in dahulu supaya bisa masuk ke halaman admin.

\section{IV.2.2 Halaman User Admin}

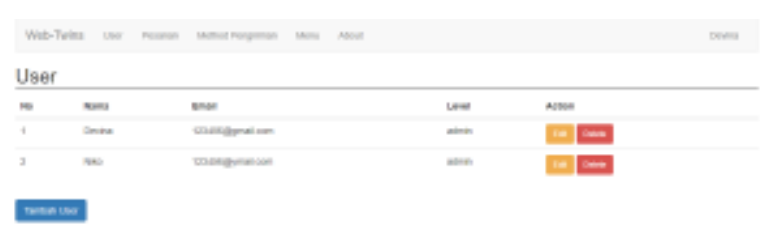

Gambar 4.7 Tampilan Halaman User Admin

Pada halaman ini admin, bisa mengatur user yang telah terdaftar menjadi admin pada web-Twins

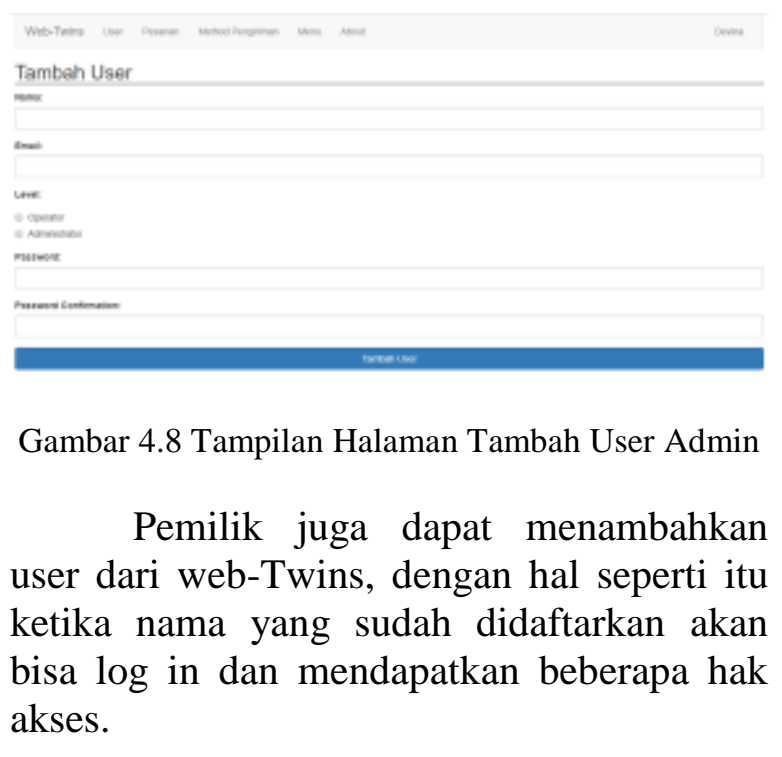




\section{IV.2.3 Halaman Pesanan}

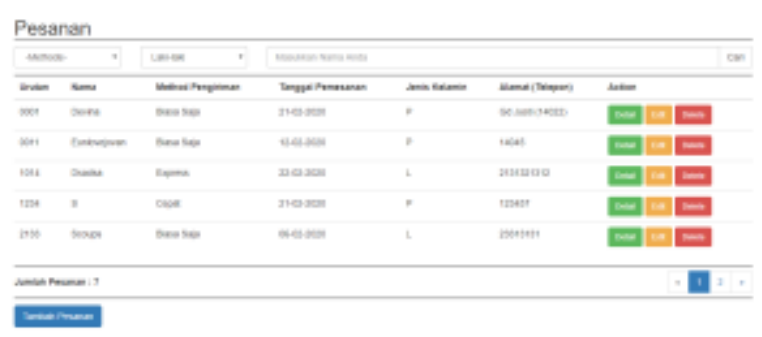

Gambar 4.9 Tampilan Halaman Pesanan Admin

Admin dapat melakukan pemeriksaan pesanan pada halaman ini, dengan adanya fitur detail, edit, dan delete. Menu detail untuk memberikan rincian informasi pelanggan yang memesan, menu edit untuk mengubah informasi dan menu delete untuk menghapus rincian pesanan jika pesanan telah selesai.

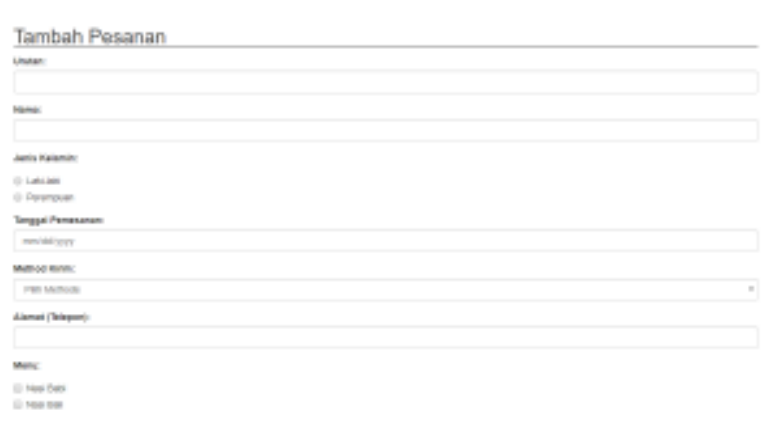

Gambar 4.10 Tampilan Halaman Tambahan Pesanan Admin

Disini admin juga bisa menambahkan rincian pesanan jika suatu saat terjadi keadaan mendesak, yang mengharuskan diinput secara manual.

\section{IV.2.4 Halaman Method Pengiriman}

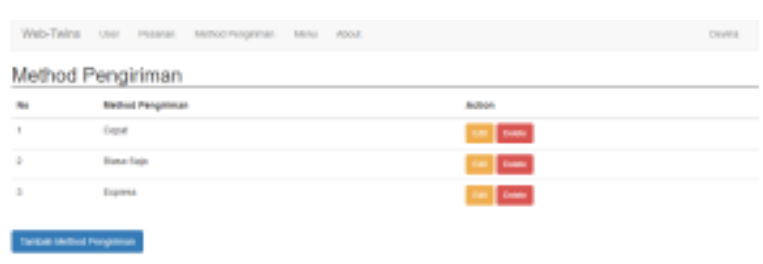

Gambar 4.11 Tampilan Halaman Method Pengiriman Admin

Admin akan menambahkan detail method pengiriman, disertai dengan fitur edit, dan delete.

\section{IV.2.5 Halaman Menu}

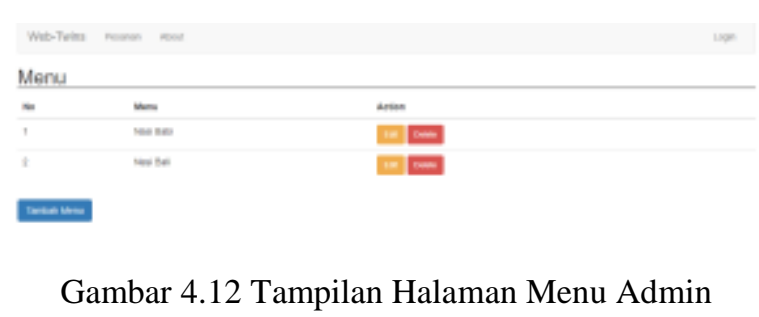

Admin akan menambahkan detail menu makanan yang dijualkan, disertai dengan fitur edit, dan delete.

\section{IV.3 Fitur Tambahan}

\section{IV.3.1 Halaman Chat}

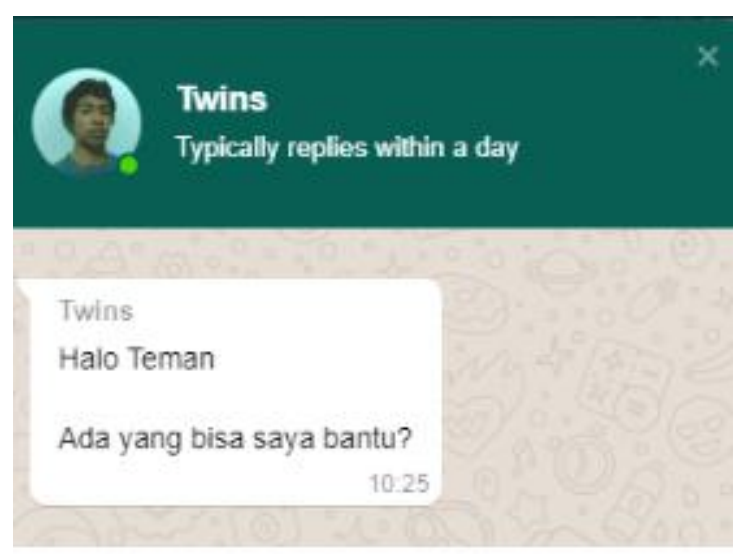

\section{(S) Start Chat}

Gambar 4.12 Tampilan Fitur Chat

Dengan hadirnya fitur ini, akan semakin mempermudah pengguna untuk berhubungan dengan kedai Twins.

\section{IV.3.2 Google Map}

\section{LOKASI KAMI}

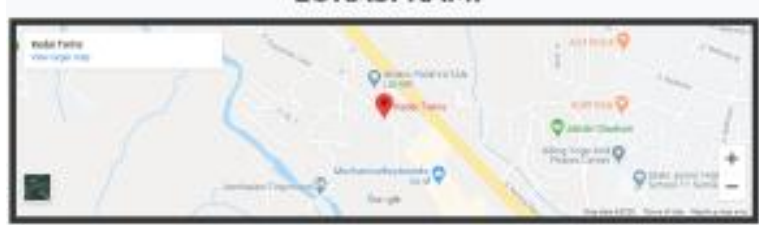

Gambar 4.12 Tampilan Fitur Map 
Fitur ini akan membantu pengguna dalam menemukan lokasi kedai Twins.

\section{IV.3.3 Video}

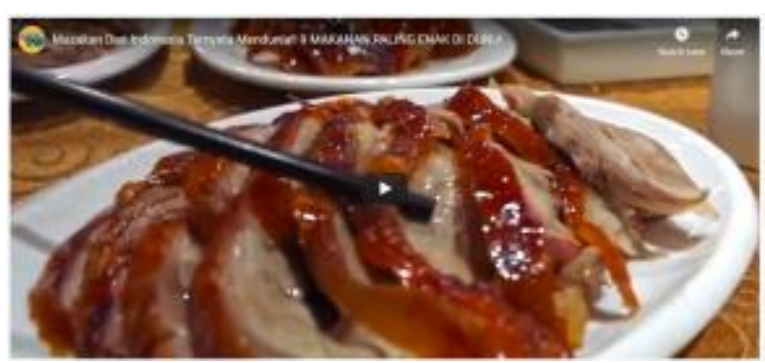

Gambar 4.13 Tampilan Fitur Video

Video ini akan menambah rasa ketertarikan pengguna pada menu kedai Twins, karena disertai dengan visual dari gambar dan suara yang menggiurkan.

\section{IV.3.4 Kalkulator}

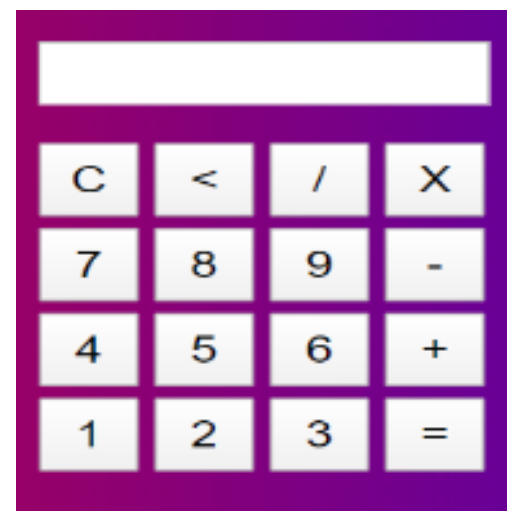

Gambar 4.13 Tampilan Fitur Kalkulator

Dengan adanya fitur kalkulator, pelanggan akan terbantu pada saat menghitung total harga makanan yang dipesannya.

\section{KESIMPULAN}

Website ini dibangun menggunakan framework Laravel dengan bahasa pemrograman PHP dan menggunakan database SQLyog. Website ini diharapkan memberikan kemudahan kepada user dalam melakukan pemesanan dan mendapat informasi pada kedai Twins, dan admin dalam melakukan pengelolaan data pada kedai Twins. Website hanya dapat diakses dan digunakan di kedai Twins.

\section{DAFTAR PUSTAKA}

[1] https://sahabatartikel.co.id/2018/03/7pengertian website-menurut-para-ahliterlengkap/ (diakses 20 Februari 2020)

[2] A. Rusmana, in The Future of Organizational Communication In The Industrial Era 4.0: Book Chapter Komunikasi Organisasi, Bandung, 2019.

[3] https://sikkola.wordpress.com/2016/02/20 /pengertian-my-sql-dan-sqlyog/ (diakses 20 Februari 2020)

[4] P. D. S. Mulyani, Analisis dan Perangangan Sistem Informasi Keuangan Daerah, Bandung: Abdi Sistematika, 2016.

[5] https://idcloudhost.com/pengertiandan keunggulan-framework-laravel/ (diakses 21 Februari 2020)

[6] D. P. Oktavian, Menjadi Programmer Jempolan Menggunakan PHP, Yogyakarta: MediaKom, 2019.

[7] Jubilee. Enterprise, Pengenalan HTML dan CSS, 2016: PT. Elex Media Komputindo, Jakarta, 2016. 